\title{
Kinetics Adsorption of Silver Ion by Blend Chitosan-Polyvinyl Alcohol Resin
}

\author{
U. Rakchaiyawan, Y. Kulratkitiwong, and K. Piyamongkala
}

\begin{abstract}
Blend chitosan-polyvinyl alcohol resin as adsorbent of silver ion was studied. Batch kinetic experiments were carried out the dosage of adsorbent between $0.1-0.5 \mathrm{~g}$ and initial concentration of silver ion in range $20.0-100.0 \mathrm{mg} / \mathrm{L}$. The experimental result showed that an increasing dosage of adsorbent and initial concentration of silver ion increased percent adsorption and adsorption capacity. The adsorption capacity of blend chitosan-polyvinyl alcohol resin at $0.5 \mathrm{~g}$ and $100 \mathrm{mg} / \mathrm{L}$ was $19.1 \mathrm{mg} / \mathrm{g}$. The pseudo-first order and pseudo-second order were employed to evaluate the kinetic model. It was found that the pseudo-second order model was fit for describing the adsorption behavior. The mechanism of silver ion adsorption onto blend chitosan-polyvinyl alcohol resin occurred in 3 steps. The rate limiting step for mechanism of adsorption was film diffusion.
\end{abstract}

Index Terms-Adsorption, chitosan-polyvinby alcohol, kinetics, silver ion.

\section{INTRODUCTION}

Silver is a precious metal widely used in the photographic, electrical, electronic, chemical and jewellery industrials. Most world silver is recovered from fractions of photographic films, X-ray films and jewellery [1]. Silver is also classified as a hazardous material and its discharge is limited to $5 \mathrm{mg} / \mathrm{L}$ in California [2]. Several methods have been reported to recover the fractions of silver in wastewater. The adsorption process is recognized to treat pollutant in wastewater. It is emerging technique and a large variety of adsorbents.

Chitosan, Poly (1, 4-2 amino-2-deoxy- $\beta$-D-glucose), is obtained by deacetylation chitin in base solution. It used as an adsorbent of pollutants in wastewater since both amino $\left(-\mathrm{NH}_{2}\right)$ groups at $\mathrm{C}-2$ and hydroxyl $(-\mathrm{OH})$ groups at $\mathrm{C}-6$ on chitosan chains which can serve as coordination and reaction sites [3]. The pollutants from wastewater, such as heavy metals and dyes can be treated by adsorption of chitosan [4], [5]. Chitosan blended with polyvinyl alcohol (PVA) had been reported to have excellent mechanical and chemical properties [6]. In this work, the removal of silver ion from aqueous solution and photography wastewater with blend chitosan-polyvinyl alcohol resins was studies. The batch

Manuscript received August 4, 2014; revised December 17, 2014. This work was supported by Faculty of Applied Science Fund of KMUTNB.

U. Rakchaiyawan, Y. Kulratkitiwong, and K. Piyamongkala are with the Department of Industrial Chemistry, Faculty of Applied Science, King Mongkut's University of Technology North Bangkok Thailand (e-mail: ploy_qeez@hotmail.com,ta-ey_sodaa@hotmail.com, kwt@kmutnb.ac.th). kinetic adsorption experiments were conducted under various dose of adsorbent and initial concentration of adsorbate.

\section{MATERIALS AND METHODS}

\section{A. Adsorbate}

Silver ion from silver nitrate was used in this study for synthesis wastewater. It was supplied by VWR International LTD. To investigate an adsorption of silver ion on the adsorbent, the photography wastewater from photography shop in Bangkok province was used for wastewater.

\section{B. Adsorbent}

Chitosan solution was prepared by dissolving $2.0 \mathrm{~g}$ of dry flake chitosan into $100 \mathrm{~cm}^{3}$ of $2 \% \mathrm{v} / \mathrm{v}$ of acetic acid solution. It was stirred by mechanical motor stirrer at speed $300 \mathrm{rpm}$ at room temperature for $24 \mathrm{~h}$ to obtain chitosan solution. Polyvinyl alcohol (PVA) solution was prepared by dissolving $8.0 \mathrm{~g}$ of power PVA into $100 \mathrm{~cm}^{3}$ of distillation water and agitated on magnetic stirrer at $70{ }^{\circ} \mathrm{C}(300 \mathrm{rpm})$ for $6 \mathrm{~h}$ to obtain PVA solution. The two solutions were blended together with stirring on the magnetic stirrer $(300 \mathrm{rpm})$ at 70 ${ }^{\circ} \mathrm{C}$ for $6 \mathrm{~h}$, and then stirring followed for $12 \mathrm{~h}$ under room temperature to obtain a homogeneous gel. The gel was dropped into $5 \% \mathrm{w} / \mathrm{v}$ of sodium tripolyphosphate solution by peristaltic pump to obtain blend chitosan-polyvinyl alcohol beads. Wet blend chitosan polyvinyl alcohol beads were filtered and washed by distillation water several times until neutral $\mathrm{pH}$. Then, the beads were cross-linked with $0.5 \% \mathrm{v} / \mathrm{v}$ of ethylene glycol diglycidyl ether (EGDE) for $24 \mathrm{~h}$ in water-ethanol mixing solution $\left(200: 200 \mathrm{~cm}^{3}\right)$ at room temperature to obtain cross-linked blend chitosan-polyvinyl alcohol beads. The cross-linked beds were washed with distillation water repeatedly and finally dried using oven at temperature $30{ }^{\circ} \mathrm{C}$ for $6 \mathrm{~h}$ to obtain blend chitosan-polyvinyl alcohol resin. The pore volume, pore diameter and surface area of blend chitosan-polyvinyl alcohol resin as calculated by BET method were $0.64 \times 10^{-3} \mathrm{~m}^{3} / \mathrm{g}, 61.05 \mathrm{~nm}$ and $3.23 \times 10^{-2}$ $\mathrm{m}^{2} / \mathrm{g}$, respectively.

\section{Adsorption Experimental}

The kinetics for silver ion adsorption was carried at in flask by adding blend chitosan-polyvinyl alcohol resin to $100 \mathrm{~cm}^{3}$ of silver ion solution. The effect of amount of adsorbent was studied in the range of $0.1-0.5 \mathrm{~g}$. The initial concentration of silver ion was studied in the range of $20.0-100.0 \mathrm{mg} / \mathrm{L}$. The samples were pipetted out at different time intervals. The supernatant solution was analyzed by Atomic Absorption Spectrometer at a wavelength $328.1 \mathrm{~nm}$. The amounts percent adsorption and adsorption capacity were computed as shown in (1) and (2), respectively. 


$$
\begin{gathered}
\text { Percent adsorption }=\left(\frac{C_{0}-C_{t}}{C_{0}}\right) \times 100 \\
q_{t, \exp }=\left(\frac{\left(C_{0}-C_{t}\right) \times V}{W}\right)
\end{gathered}
$$

where $C_{0}$ is initial concentration of silver ion $(\mathrm{mg} / \mathrm{L}), C_{t}$ is concentration of silver ion at time $(\mathrm{mg} / \mathrm{L}), q_{t, \exp }$ is adsorption capacity of silver ion at time from experiment $(\mathrm{mg} / \mathrm{g}), V$ is volume of silver ion solution (L) and $W$ is mass of blend chitosan-polyvinyl alcohol resin $(\mathrm{g})$.

\section{RESUlTS AND DisCUSSION}

\section{A. Effect Dose of Adsorbent}
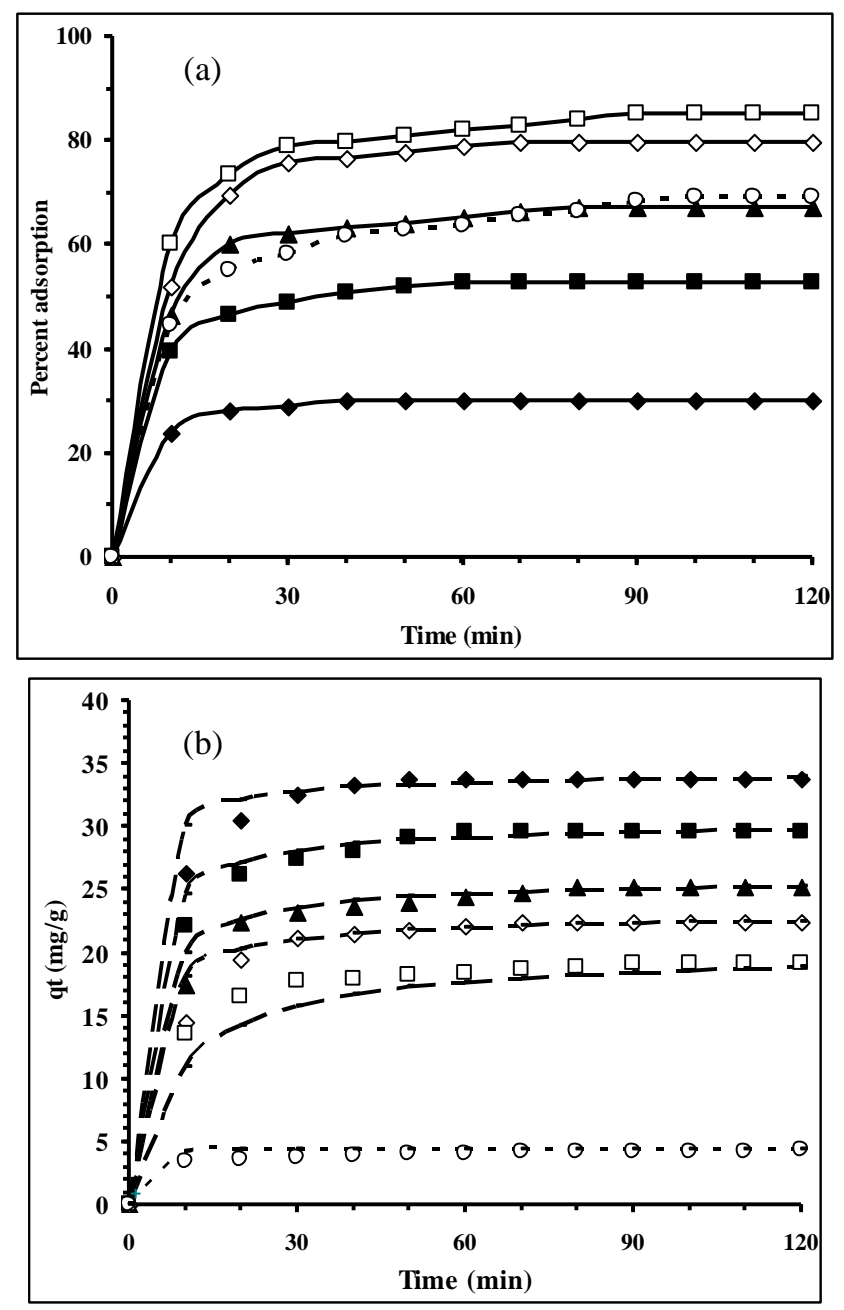

Fig. 1. Effects of contact time on; (a) percent adsorption and (b) adsorption capacity: for adsorbent dose; $\diamond .1, \square 0.2, \boldsymbol{\Delta} 0.3, \diamond 0.4, \square 0.5 \mathrm{~g}$ and $\circ$ photography wastewater.

The effect of blend chitosan-polyvinyl alcohol resin dosage from $0.1-0.5 \mathrm{~g}$ for adsorption the silver ion shows in Fig. 1(a). It was found that, increase in the dose of adsorbent leads to an increase in the percent adsorption. The percent adsorption was rapid at the initial period of contact time, and became slow and even reached equilibrium when the adsorption was in progress. In the first $10 \mathrm{~min}$, the percent adsorption was 23.9-60.1\%, when dose of blend chitosan-polyvinyl alcohol resin increased from $0.1-0.5 \mathrm{~g}$, respectively. At equilibrium occurred at $30 \mathrm{~min}$, the percent adsorption increased to 29.0-78.8\%. An increase in the percent adsorption with the adsorbent dosage can be attributed to greater surface area and the availability of more adsorption sites of adsorbent [7]. The percent adsorption of silver from photography wastewater by blend chitosan-polyvinyl alcohol resin was $69.1 \%$. In contrast, at equilibrium the adsorption capacity decrease from $33.7-19.1 \mathrm{mg} / \mathrm{g}$, when dose of adsorbent increased from 0.1-0.5 g, respectively, shows in Fig. 1(b). The drop in adsorption capacity is basically due to the sites remaining unsaturated during the adsorption. Similar trend has also been reported by chromium (VI) adsorption onto sawdust [8]. The adsorption of silver ion onto blend chitosan-polyvinyl alcohol resin occurred due to free lone pairs electrons on the amino nitrogen are suitable for coordination with silver ion to give the corresponding adsorbent-metal complex [9]. The adsorption capacity of silver from photography wastewater by blend chitosan-polyvinyl alcohol resin was $4.3 \mathrm{mg} / \mathrm{g}$.

\section{B. Effect of Initial Concentration}

The adsorption capacity of silver ion of blend chitosan-polyvinyl alcohol resin as a function of contact time and initial silver ion concentration is presented in Fig. 2(a). The adsorption capacity of silver ion at $20.0-100.0 \mathrm{mg} / \mathrm{L}$ onto blend chitosan-polyvinyl alcohol resin increases within the first 30 minute of contact time. There is no change in the adsorption capacity when the contact time is longer. In the first 30 minute, the adsorption rate of silver ion onto blend chitosan-polyvinyl alcohol resin occur rapidly and thereafter the adsorption proceeds is slowly rate until to the finally attains equilibrium of adsorption. When the initial silver ion concentration was increased from $20.0-100.0 \mathrm{mg} / \mathrm{L}$, the adsorption capacity increased from $3.0-19.1 \mathrm{mg} / \mathrm{g}$, respectively.

The higher sorption rate at the initial period may be due to the number of available adsorption sites at the initial stage of adsorption process, as a result there exist increased concentration gradients between adsorbate in solution and adsorbate in the adsorbent surface. This increased concentration gradient tends to increase the rate at which silver ion is adsorbed at the initial stage of adsorption. This concentration gradient is reduced with increasing contact time because of accumulation of silver ion on the vacant adsorption sites which invariably leads to decreased adsorption of silver ion at the later stages of adsorption. While, the adsorption capacity increases with the increase in initial silver ion concentration due to in the driving force of silver ion between solution and surface of adsorbent [10].

\section{Kinetics of Adsorption}

The linear pseudo-first order and pseudo-second order, and non-linear kinetic models are shown in (3), (4) and (5), respectively [11].

$$
\begin{gathered}
\log q_{e, \text { exp }}-\log q_{t, \exp }=\log q_{e, \text { cal }}-\left(k_{1} t / 2.303\right) \\
\left(t / q_{t, \exp }\right)=\left(1 /\left(k_{2} q_{e, \exp }{ }^{2}\right)+\left(t / q_{e, \text { cal }}\right)\right. \\
q_{t, \text { cal }}=\left(q_{e, \text { cal }}^{2} k_{2} t\right) /\left(1+\left(q_{e, \text { cal }} k_{2} t\right)\right)
\end{gathered}
$$

where, where $q_{e, \text { exp }}$ is adsorption capacity of silver at equilibrium from experiment $(\mathrm{mg} / \mathrm{g}), q_{e}$, cal is adsorption 
capacity of silver ion at equilibrium from calculate $(\mathrm{mg} / \mathrm{g}), q_{t}$, cal is adsorption capacity of silver ion at time from calculate $(\mathrm{mg} / \mathrm{g}), k_{1}$ is rate constant of pseudo-first order $\left(\mathrm{min}^{-1}\right), k_{2}$ is rate constant of pseudo-second order ( $\mathrm{g} / \mathrm{mg}$-min) and $\mathrm{t}$ is time of adsorption (min).

The linear plot of pseudo-first order is not shown. While the linear plot of $t / q_{t}$ versus $t$ is shown in Fig. 2(b). A comparison of the results is shown in Table I. The correlation coefficients for the pseudo-second order are greater than pseudo-first order. The adsorption capacity obtain from calculate accords very well with the adsorption capacity from experiment. The non-linear plots of pseudo-second order show a good agreement between experimental and calculated (Fig. 1(b) and Fig. 2(a)). This suggests that the adsorption of silver ion onto blend chitosan-polyvinyl alcohol resin is a pseudo-second order.
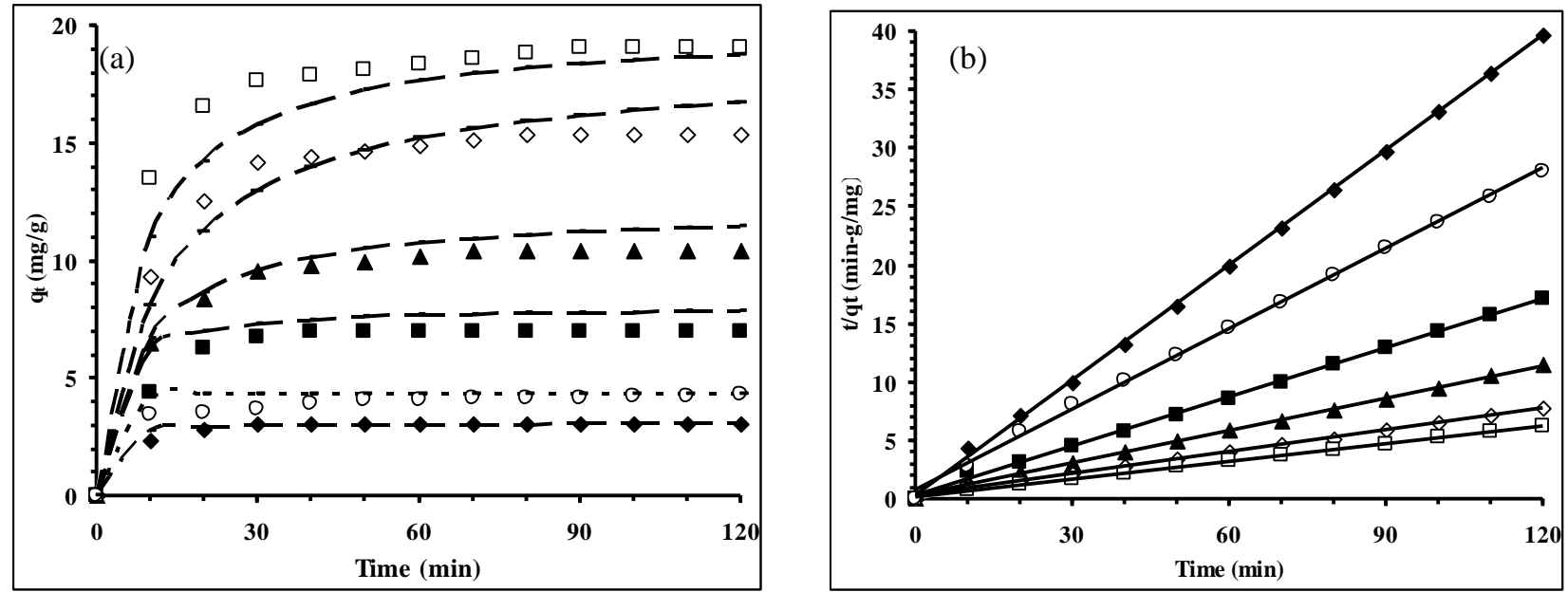

Fig. 2. Effects of contact time on; (a) adsorption capacity and (b) pseudo-second order: for initial concentration; $\bullet 20.0, \square 40.0, \boldsymbol{\Delta} 60.0, \diamond 80.0, \square 100.0 \mathrm{~g}$ and o photography wastewater.

TABLE I: RATE CONSTANT OF SILVER ION ADSORPTION ONTO BLEND CHITOSAN-POLYVINYL AlCOHOL RESIN

\begin{tabular}{|c|c|c|c|c|c|c|c|c|c|c|c|}
\hline & & \multirow{2}{*}{$q_{e, \exp }$} & \multicolumn{3}{|c|}{ Pseudo first order } & \multicolumn{3}{|c|}{ Pseudo second order } & \multicolumn{3}{|c|}{ Intraparticle diffusion } \\
\hline & & & $q_{e, c a l}$ & $k_{1}$ & $R^{2}$ & $q_{e, c a l}$ & $k_{2}$ & $R^{2}$ & $k_{i, 1}$ & $k_{i, 2}$ & $k_{i, 3}$ \\
\hline \multirow{5}{*}{ Dose $(\mathrm{g})$} & 0.1 & 37.7 & 1.1 & 0.031 & 0.021 & 34.2 & 0.021 & 0.996 & 2.76 & 0.06 & - \\
\hline & 0.2 & 29.7 & 1.2 & 0.030 & 0.061 & 30.3 & 0.014 & 0.997 & 2.30 & 1.17 & - \\
\hline & 0.3 & 25.2 & 1.3 & 0.242 & 0.957 & 25.8 & 0.013 & 0.998 & 2.58 & 0.35 & - \\
\hline & 0.4 & 22.4 & 1.3 & 0.018 & 0.672 & 23.0 & 0.016 & 0.996 & 2.93 & 0.18 & - \\
\hline & 0.5 & 19.1 & 13.0 & -0.003 & 0.981 & 20.1 & 0.003 & 0.996 & 3.16 & 0.71 & 0.26 \\
\hline \multirow{5}{*}{$\begin{array}{c}\text { Concentration } \\
(\mathrm{mg} / \mathrm{L})\end{array}$} & 20.0 & 3.0 & 2.8 & -0.129 & 0.993 & 3.1 & 0.305 & 0.999 & 0.96 & 0.01 & - \\
\hline & 40.0 & 7.0 & 7.3 & -0.114 & 0.989 & 8.0 & 0.042 & 0.997 & 1.19 & 0.03 & - \\
\hline & 60.0 & 10.5 & 7.8 & -0.060 & 0.975 & 12.2 & 0.010 & 0.998 & 1.20 & 0.07 & - \\
\hline & 80.0 & 15.4 & 11.6 & -0.019 & 0.672 & 15.2 & 0.005 & 0.996 & 1.81 & 0.08 & - \\
\hline & 100.0 & 19.1 & 13.0 & -0.003 & 0.981 & 20.1 & 0.003 & 0.996 & 3.16 & 0.71 & 0.26 \\
\hline \multicolumn{2}{|c|}{ Photography wastewater } & 4.3 & 1.8 & -0.036 & 0.896 & 4.4 & 0.071 & 0.999 & 0.11 & - & - \\
\hline
\end{tabular}

The intraparticle diffusion rate equation can be written as follows (6).

$$
q_{t, \exp }=k_{i, d} t^{0.5}+C
$$

where, $k_{i, d}$ is rate constant of intraparticle diffusion $(\mathrm{mg} / \mathrm{g}) / \mathrm{min}^{0.5}$ and $C$ is the diffusion effect of boundary layer $(\mathrm{mg} / \mathrm{g})$

The $k_{i, d}$ is the slope of portions straight line of plot $q_{t, \text { exp }}$ verses $t^{0.5}$. The initial rates of intraparticle diffusion are obtained by linearization of the curve $q_{t}=f t^{0.5}$. The plot may present a multi-linearity, which means two or more stages occur [12]. The slope of each stage is termed as the rate parameters $k_{i, d}(d=1-3)$. Table I shows the rate parameters for dose of adsorbent and initial concentrations of silver ion adsorption onto blend chitosan-polyvinyl alcohol resin. It is clearly seen that the first stage is an instantaneous adsorption stage. The second stage is the gradual adsorption, is the stage where the intraparticle diffusion in controlled and the third stage is the final equilibrium stage where the intraparticle starts to slow down due to extremely low of adsorbate concentration.

The kinetics data were further analyzed using the kinetic to check whether sorption proceeds via external diffusion or intraparticle diffusion mechanism, which is expressed as follows (7).

$$
F=1-\frac{6}{\pi^{2}} e^{-B t}
$$

where, $B$ is a constant and $F$ is the fractional attainment of equilibrium at time $t$ in (8).

$$
F=\frac{q_{t, \exp }}{q_{e, \exp }}
$$


To compute $B t,(8)$ is substituted by (7) and the kinetic expression becomes (9).

$$
B t=-0.4977-\ln \left(1-\frac{q_{t, \exp }}{q_{e, \exp }}\right)
$$

Thus, the value of $B t$ can be computed for each value of $\mathrm{F}$, and then plotted against time. Linearity of this plot is employed to distinguish between external-transport (film diffusion) and intraparticle transport controlled rates of sorption. A straight line passing through the origin is indicative of sorption processes governed by particle-diffusion mechanisms; otherwise governed by film diffusion [13]. In the present case the plots were neither linear nor passed through the origin Fig. 3(b) and Fig. 4(b). These indicate that film diffusion is the rate-limiting sorption process for silver ion onto blend chitosan-polyvinyl alcohol resin.
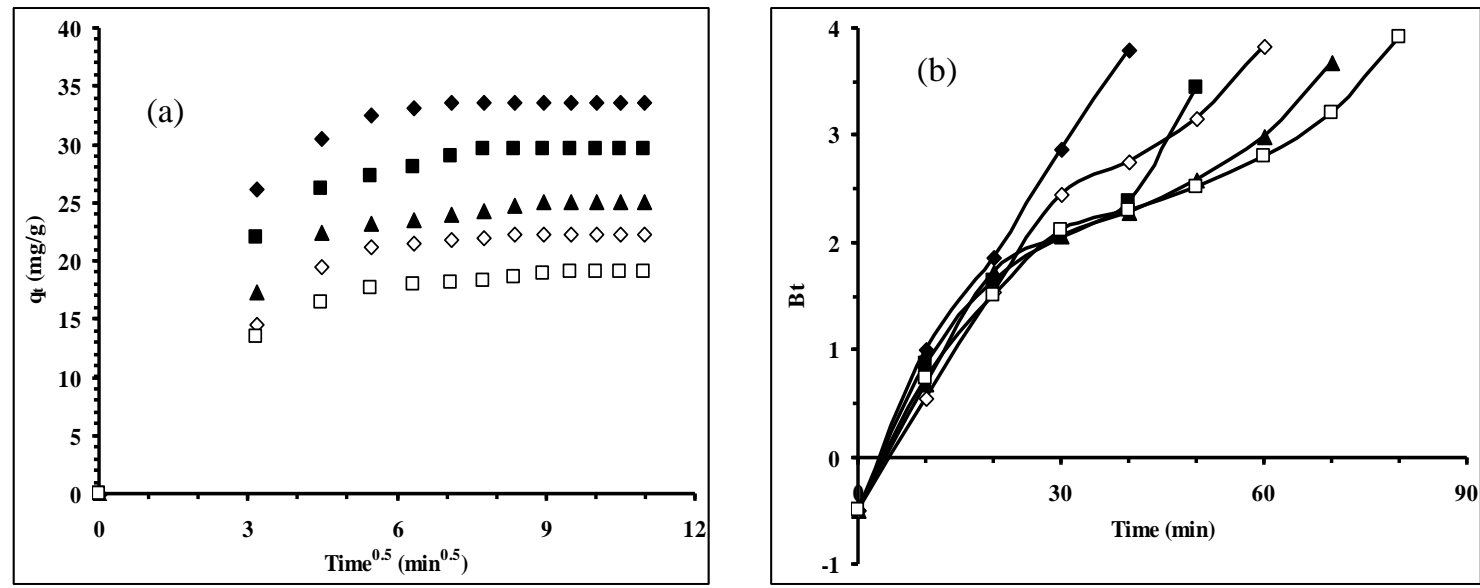

Fig. 3. Mechanism of adsorption (a) intraparticle diffusion and (b) rate limiting step: for adsorbent dose; $\bullet .1, \square 0.2, \boldsymbol{\Delta} 0.3, \diamond 0.4$ and $\square 0.5 \mathrm{~g}$.
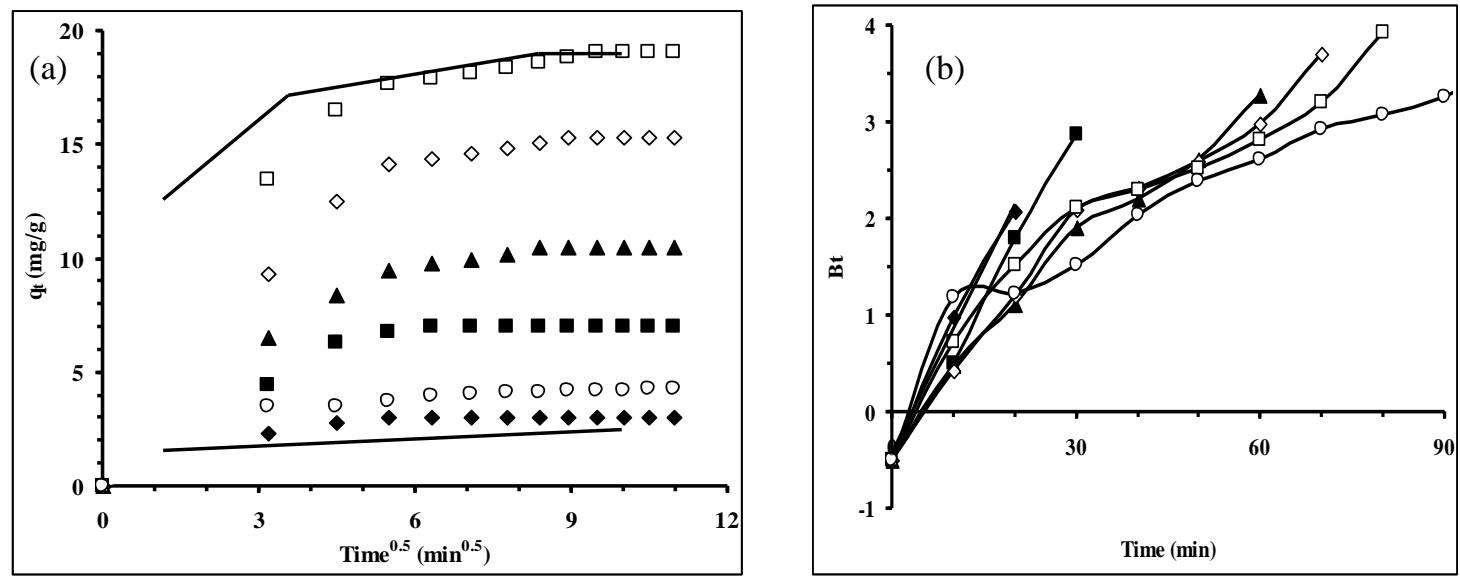

Fig. 4. Mechanism of adsorption (a) intraparticle diffusion and (b) rate limiting step: for initial concentration; $\bullet 20.0, \square 40.0, \boldsymbol{\Delta} 60.0, \diamond 80.0, \square 100.0 \mathrm{~g}$ and $\circ$ photography wastewater.

\section{CONCLUSION}

The adsorption capacity of silver ion from aqueous solution onto blend chitosan-polyvinyl alcohol resin was $19.1 \mathrm{mg} / \mathrm{g}$. Kinetics adsorption showed to fit well in pseudo-second order, confirming the chemisorption of silver ion and silver from photography wastewater onto blend chitosan-polyvinyl alcohol resin. The mechanism of adsorption involved in 3 steps. The rate limiting step was controlled by film diffusion.

\section{ACKNOWLEDGMENT}

This research was funded by Faculty of Applied Science, King Mongkut's University of Technology North Bangkok.

\section{REFERENCES}

[1] L. Wang, R. Xing, S. Liu, H. Yu, Y. Qin, K. Li, J. Feng, R. Li, and P. $\mathrm{Li}$, "Recovery of silver (I) using a thiourea-modified chitosan resin," $J$. Hazard Mater., vol. 180, pp. 577-582, 2010.
[2] C. Songkroah, W. Nakbanpote, and P. Thiravetyan, "Recover of silver-thiosulphate complexes with chitin," Process Biochem., vol. 39, pp. 1553-1559, 2004.

[3] M. N. V. R. Kumer, "A review of chitin and chitosan application,' React Funct Polym., vol. 46, pp. 1-27, 2000.

[4] A. Gamage and F. Shahidi, "Use of chitosan for the removal of metal ion contaminants and proteins from water," Food Chemistry, vol. 104, pp. 989-996, 2007.

[5] G. Z. Kyzas, K. Kostoglou, and N. K. Lazaridis, "Relating interactions of dye molecules with chitosan to adsorption kinetic data," Langmuir, vol. 26, no. 12, pp. 9617-9626, 2010.

[6] L, Jin and R. Bai, "Mechanisms of lead adsorption on chitosan/PVA hydrogel beads," Langmuir, vol. 18, no. 25, pp. 9765-9770, 2002.

[7] Y. Nuhoglu and E. Oguz, "Removal of copper (II) from aqueous solutions by biosorption on the cone biomass of Thuja orientalis," Process Biochem., vol. 38, pp. 1627-1631, 2003.

[8] S. S. Baral, S. N. Das, and P. Rath, "Hexavalent chromium removal from aqueous solution by adsorption on treated sawdut," Biochem Eng. J., vol. 31, pp. 216-222, 2006.

[9] H. A. Shawky, "Synthesis of ion-imprinting chitosan/PVA crosslinked membrane for selective removal of Ag (I)," J. Appl Polym Sci., vol. 114, pp. 2608-2615, 2009. 
[10] C. Septhum, S. Rattanaphani, J. B. Bremner, and V. Rattanaphani, "An adsorption study of $\mathrm{Al}$ (III) ions onto chitosan," J. Hazard Mater., vol. 148, pp. 185-191, 2007

[11] A. M. Donia, A. A. Atia, and K. Z. Elwakeel, "Recovery of gold (III) and silver (I) on a chemically modified chitosan with magnetic properties," Hydrometallurgy, vol. 87, pp. 197-206, 2007.

[12] J. U. K. Oubagaranadin, N. Sathyamurthy, and Z. V. P. Murthy, "Evaluation of fuller's earth for the adsorption of mercury form aqueous solution: A comparative study with activated carbon," $J$. Hazard Mater., vol. 142, pp. 165-174, 2007.

[13] D. Mohan and K. P. Singh, "Single-and multi-component adsorption of cadmium and zinc using activated carbon derived from bagasse-an agricultural waste," Water Res., vol. 36, pp. 2304-2318, 2002.

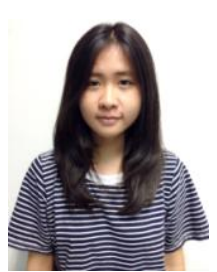

U. Rakchaiyawan was born in Nakhon Pathom province, Thailand in September 1988. She received the undergraduate degree in industrial chemistry from Faculty of Applied Science, King Mongkut's University of Technology North Bangkok (KMUTNB) in 2012.

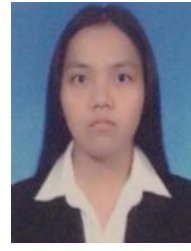

Y. Kulratkitiwong was born in Nakhon Pathom province, Thailand in September 1989. She received the undergraduate degree in industrial chemistry from Faculty of Applied Science, King Mongkut's University of Technology North Bangkok (KMUTNB) in 2012.

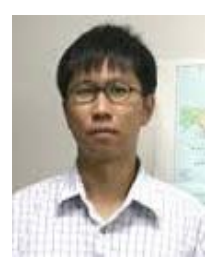

K. Piyamongkala is a lecturer in the Department of Industrial Chemistry, Faculty of Applied Science, King Mongkut's University of Technology North Bangkok (KMUTNB). His research and teachings' experience are in industrial wastewater adsorption and industrial waste treatment extends for over 15 years. He obtained his undergraduate degree from King Mongkut's Institute of Technology North Bangkok, Thailand in 1992, master degree at King Mongkut's Institute of Technology Thonburi, Thailand in 1996, and PhD degree in 2008 from The Chulalongkorn University, Thailand. 